\title{
Muscular activation differences between professional and amateur soccer players during countermovement jump
}

\author{
Ali Onur CERRAH ${ }^{1}$, Elvin ONARICI GUNGOR ${ }^{1}$, Abdullah Ruhi SOYLU², Hayri ERTAN ${ }^{1}$
}

${ }^{1}$ Sport Sciences Faculty, Anadolu University, İki Eylül Campus, Eskişehir, Turkey

${ }^{2}$ School of Medicine Biophysics Department, Hacettepe University, Ankara, Turkey

Address correspondence to A. O. Cerrah, e-mail:aocerrah@anadolu.edu.tr

\begin{abstract}
The purpose of this study was to compare the muscular activation strategies of professional and amateur soccer players during countermovement jump. Twenty male soccer players, consisting of 10 amateurs (age: $22.9 \pm 3.1$ year, training status: $12.2 \pm 3.1$ year) and 10 professionals (age: $22.2 \pm 2.5$ year, training status: $13.7 \pm 2.7$ year) volunteered to participate in the study. Dominant leg surface electromyography activities of five muscles were recorded during countermovement jump. In addition, isokinetic strength of knee flexor and extensors, peak and average power were calculated. According to our results, the average countermovement jump heights were calculated for amateurs $(37.1 \pm 3.12 \mathrm{~cm})$ and professionals $(41.3 \pm 2.58 \mathrm{~cm})$. Furthermore, gastrocnemius muscle activation occurred significantly higher in professional soccer players than that of the amateur soccer players during propulsion (between $-150 \mathrm{~ms}$ and $-120 \mathrm{~ms}$ ) and flight phase (between 150ms and 270ms) $(\mathrm{p}<0,05)$. Rectus femoris, vastus lateralis, vastus medialis and biceps femoris muscles contraction values were almost similar in both amateur and professional soccer players which their age, training year and muscle strengths are similar. It could be concluded that preactivation and post landing phase are important for the jumping performance for both groups; however; the high activation of gastrocnemious muscle could be one of the important determinant for the superior jump performance
\end{abstract}

Keywords: Professional, amateur, electromyography, muscular strength, jump power.

\section{INTRODUCTION}

In soccer game, many explosive movements are performed by soccer players like kicking, tackling, jumping, turning, sprinting, and changing pace (25). Among these explosive movements, jumping is one of the important skills.

Jumping is known as one of the complex movements that require complex motor coordination between upper and lower body segments (5) and it is defined that the differences in vertical jump technique and/or coordination may exist between athletes and non-athletes (14). Furthermore, Canavan (6) underlines why countermovement jump (CMJ) is prefered rather than static squat jump (SJ) when assessing athletes. It is stated that SJ begins from a paused squat position before jumping vertically, whereas CMJ begins from an erect position and uses a quick crouching action followed immediately by a vertical jump (6) and it has been described abundantly that people jump higher in CMJ than in SJ (13). CMJ has been considered particularly suited for evaluating explosive characteristics of elite athletes (21) like specific jump performance in soccer.
According to literature, CMJ performance is one of the most important performance determinants for soccer. CMJ performance is related to strength and power $(1,10)$ and the coordination among muscles (stretch-shortening cycle [SSC]). Bobbert (4) underlines the importance SSC during $\mathrm{CMJ}$, which may help to incrase the work produced. It is stated that energy is absorbed in active muscle elastic elements in pre-stretched phase and later it is reutilized in the concentric action of muscles (4). However, it is not clear whether the role of leg muscle activation, jump power, and maximal strength parameters for $\mathrm{CMJ}$ performance differ between amateur and professional soccer players. Although there are some studies documenting hip flexors, knee extensors-flexors and ankle plantar flexors muscular activation differences during CMJ for different situations $(17,23,27)$, limited study conducted between amateur and professional soccer players. Moreover, these documented EMG data's related to jumping were given as means and standard deviations $(11,20,21,23)$ rather than the whole jump EMG characteristic in time domain to identify superior jump performance and muscular coordination. 
The primary purpose of this study was to compare the muscular activation strategies of professional and amateur soccer players who are in the same age group and have same training experience during countermovement jump. It was hypothesized that different level soccer players should have developed different muscular activation strategies. It is also important to understand how the jump power and strength parameters change according to players skill level and whether or not the effect of these parameters on muscular activations are important between homogenous groups in the case of age, training experience and playing position.

\section{MATERIAL \& METHODS}

\section{Participants}

Twenty male soccer players, 10 amateurs (age: 22.9 \pm 3.1 year, training status: $12.2 \pm 3.1$ year) and 10 professional (age: 22.2 $\pm 2.5 y e a r$, training status: $13.7 \pm 2.7$ year), volunteered to participate during the 2009-2010 soccer season. All players gave written consent to participate in the study. None of the subjects had any previous injuries of their lower limbs. Subjects were recruited using the snowball sampling method and selected randomly from the player list. Tests were performed between 13:0016:00 in laboratory conditions and lasted approximately 45 minutes per subject. The investigation was approved by the local University Ethics Committee.

\section{Measures}

Jump Test and Power Assessment: Maximal CMJ height was assessed using a special designed rubber-switch (jumping) mat $(70 \mathrm{~cm} \times 70 \mathrm{~cm})$, which copper cables placed on the surface of mat $2 \mathrm{~cm}$ distance between each. Moreover, a copper plate placed under dominant leg shoe of subjects to determine jumping height. While the subject performed a CMJ, the copper plates touch each other and send the \pm 5 Volt TTL signal to the bio vision EMG system as described in Onaricı Gungor et al., (22). By this way, the maximum jump height was calculated using the formula $[\mathrm{H}=1 / 2 \mathrm{gt} 2]$, where " $\mathrm{H}$ " is height, $\mathrm{g}$ is gravity, and $\mathrm{t}$ is flight time (7).

Peak power (Ppow) and average power (Apow) were estimated using the Johnson and Bahamonde (18) Formula;

Ppow $(W)=78.6 \cdot V J(\mathrm{~cm})+60.3 \cdot \operatorname{mass}(\mathrm{kg})-15.3 \cdot$ height $(\mathrm{cm})-1,308$

Apow $(W)=43.8 \cdot V J(\mathrm{~cm})+32.7 \cdot \operatorname{mass}(\mathrm{kg})-16.8 \cdot$ height $(\mathrm{cm})+431$

This formula for peak and average power estimation was chosen because a) average power calculated from the vertical jump test, using the countermovement jump and b) these equation use the additional factor of body height (18).

The subjects' take-off and first touch to the ground were determined as the zero level for the given movement pattern. The muscular activation patterns were divided into two sides as pre and post contact time (22). Subjects were instructed to begin from a standing position and perform a crouching action immediately followed by a jump for maximal height. Subject's hands remained on the hips for the entire movement to eliminate any influence of arm swing $(6,29)$. Furthermore, a video camera (25fps) (Canon HG 21) was placed perpendicular to the lateral side of the player to identify knee flexion angle during propulsion phase, jumps between 8090 degree knee angle were analyzed. Jump technique was demonstrated to each subject, followed by two submaximal attempts. Three maximal jumps were completed with 3-4 minutes rest between repetitions.

Table 1. Descriptive statistic of amateur and professional soccer players.

\begin{tabular}{|c|c|c|c|c|c|}
\hline \multirow{2}{*}{ Players } & \multirow{2}{*}{ Number of Training per Week } & \multirow{2}{*}{ Part of Season During Testing } & \multicolumn{3}{|c|}{ Position } \\
\hline & & & Defense & Midfielder & Forward \\
\hline Amateur $(n=10)$ & $4-5$ & In Last Month of Season & 3 & 4 & 3 \\
\hline Professional $(\mathrm{n}=10)$ & $5-7$ & In Last Month of Season & 2 & 5 & 3 \\
\hline
\end{tabular}




\section{Electromyography Recording}

Surface electromyography (EMG) activity of rectus femoris (RF), vastus lateralis (VL), vastus medialis (VM), long head of biceps femoris (BF) and medial gastrocnemius (GAS) were recorded during CMJ jump and the best value used as the outcome measurement. All EMG data were measured on the dominant leg of the subjects using bipolar surface electrodes. The dominant leg was determined based on the subject's preferred foot used to kick a ball. Electrode sites were prepared by shaving, abrading and cleansing the area. The distance between two electrodes was $2 \mathrm{~cm}$ and they were positioned longitudinally along each muscle. The reference electrode was placed on the lateral malleolus, which was found to be a neutral site. Maximum voluntary isometric contractions (MVIC) of the quadriceps (RF, $\mathrm{VL}, \mathrm{VM}$ ) were assessed by knee extension when in a sitting position with the knee at $65^{\circ}\left(0^{\circ}\right.$ full extension) while MVIC of the hamstrings (long head of BF) was assessed in a prone position with the knee at $30^{\circ}$. In order to determine the MVIC of the GAS muscle, subjects were asked to plantar flex against a resistance while in the supine position (8). The EMG signals were recorded (Biovision, Germany) with a maximum intra-electrode impedance and minimum CMMR of $6 \mathrm{k}-\mathrm{Ohm}$ and $95 \mathrm{~dB}$, respectively. Analogue signals were band pass filtered between $8-500 \mathrm{~Hz}$ and digitized by a 12-bit A/D converter at $1000 \mathrm{~Hz}$. Raw EMG data were epoched starting from $600 \mathrm{~ms}$ prior to and ending after the ground contact, full wave rectified, normalized with respect to maximum voluntary isometric contractions (MVIC) and filtered by creating linear envelops (LE) for each participant (8). Because jump height and flight time is different for all soccer players, to provide standardization data was presented with two graphs for each muscle. Recording (time) window has divided into two events. The first event represented before and after take-off time whereas the second event represented before and after landing time. Two separate graphs have been drowned by overlapping EMG data on " 0 " point for each moment.

\section{Isokinetic Test}

The isokinetic tests were performed one hour after the jump performance. A 5-min warm-up consisting of cycling (Monark) preceded the actual test. Bilateral concentric isokinetic strength of the knee extensors and flexors were measured using the Cybex isokinetic dynamometer (model 770, Humac Norm Testing and Rehabilitation System, USA). The dynamometer was calibrated according to manufacturer prescription before test trials. Measurements were done when the subjects in the sitting position. Trunk, pelvis, thigh and thorax were fixed to avoid uncomfort movement. The dynamometer rotation axis belt was fastened from the ankle of subject. The range of motion for the knee was from $90^{\circ}$ to $0^{\circ}$. Muscle strength was measured at angular velocities of 60 and $240^{\circ} \mathrm{s}^{-1}$. Angular velocities were adjusted randomly for each subject. For each test, three submaximal efforts were performed for familiarization before the maximal test. A $30 \mathrm{~s}$ rest period was given between the submaximal whereas a 2 minutes rest period was given between angular velocity tests. Five trials at each velocity were performed, and the maximal peak torque for absolute and relative knee extension, flexion, and hamstring/quadriceps ratio was measured by the Humac (2004) via computer, (4.5.5 version, CSMI, USA) and the best value used as the outcome measurement (8).

\section{Statistical Analysis}

Descriptive statistics were applied to identify the characteristics of the subjects and groups. Mean scores were calculated for each subject's 3 CMJ and averaged across each group. CMJ height, isokinetic data and jump powers were expressed as mean \pm SD. EMG data were expressed graphically as mean and standard error (SE). The Kolmogorov-Smirnov normality test was used to determine if the data were normally distributed. A Levene-test was used to determine homogeneity of variance and a student t-test was used to compare values related to above parameters between groups. The level of significance was set at $\mathrm{p}<0.05$.

\section{RESULTS}

\section{CMJ Performance Test}

Professionals $(41.3 \pm 2.58 \mathrm{~cm})$ produced a significantly higher $(\mathrm{p}<0.05)$ countermovement jump height than amateurs $(37.1 \pm 3.12 \mathrm{~cm}$ ) (Table 2).

\section{Jump Power Test}

Professionals produced a significantly higher $(\mathrm{p}<0.05)$ peak and average power (Ppow: $5040.3 \pm$ 340.4W; Apow: $1705.2 \pm 166.9 \mathrm{~W})$ than amateurs (Ppow: $4513.6 \pm 447 \mathrm{~W}$; Apow: $1463.9 \pm 236.9 \mathrm{~W}$ ) (Table 2).

\section{Isokinetic test}

As angular velocity increased, force output declined for both knee flexion and extension (Table 2). There was only one significant difference 
between the soccer player skill levels. Professionals showed higher $240^{\circ} \mathrm{s}^{-1}$ flexion strength than the amateurs among absolute and relative flexion, extension, and $\mathrm{H} / \mathrm{Q}$ ratio strength.

Even though there was one significant difference, almost all of the strength parameters tended to have a similar peak torque over all speeds and testing parameters.

\section{Electromyography test}

Graphics have been presented as Event 1 and Event 2 as described method section. EMG profiles for professional and amateur players as a percentage of MVIC are given in Figure 1 (RF-BF), Figure 2 (VM-VL) and Figure 3 (GAS) respectively. Black horizontal lines represent statistically significant differences $(p<0.05)$ between the two groups at each time point. Drawn above the graphs are the standard errors at each time point.

Table 2. A comparison of CMJ height, height, body mass, peak jump power, average jump power, peak torque values $(\mathrm{Nm})$ of dominant absolute and relative knee flexors and extensors and flexor/extensor ratio $(\mathrm{H} / \mathrm{Q})$ of professional and amateur soccer players at 60 and $240^{\circ} . \mathrm{s}^{-1}$ angular velocities.

\begin{tabular}{|c|c|c|c|}
\hline \multirow{2}{*}{\multicolumn{2}{|c|}{ Angular Velocity }} & \multirow{2}{*}{$\begin{array}{c}\text { Amateur }(\mathrm{n}=10) \\
\text { Mean } \pm \mathrm{SD}\end{array}$} & \multirow{2}{*}{$\frac{\text { Professional }(\mathrm{n}=10)}{\text { Mean } \pm \text { SD }}$} \\
\hline & & & \\
\hline $\mathrm{CMJ}(\mathrm{cm})$ & & $37.1 \pm 3.12$ & $41.3 \pm 2.58^{* *}$ \\
\hline Height $(\mathrm{cm})$ & & $171.6 \pm 6.05$ & $177.4 \pm 6.68$ \\
\hline Body Mass (kg) & & $70.1 \pm 6.69$ & $74.7 \pm 6.41$ \\
\hline Peak Power $(\mathrm{W})$ & & $4513.6 \pm 447.5$ & $5040.3 \pm 340.4^{* *}$ \\
\hline Average Power (W) & & $1463.9 \pm 236.9$ & $1705.2 \pm 166.9^{*}$ \\
\hline \multirow{2}{*}{ Knee Extension (Nm) } & $60^{\circ} \cdot \mathrm{s}^{-1}$ & $192.1 \pm 25.6$ & $203.1 \pm 26$ \\
\hline & $240^{\circ} \cdot \mathrm{s}^{-1}$ & $108.8 \pm 8.7$ & $121.8 \pm 20.3$ \\
\hline \multirow{2}{*}{ Knee Flexion (Nm) } & $60^{\circ} \cdot \mathrm{s}^{-1}$ & $145.9 \pm 22.9$ & $169.5 \pm 36.5$ \\
\hline & $240^{\circ} \cdot \mathrm{s}^{-1}$ & $92.6 \pm 15.5$ & $116.6 \pm 26.3^{*}$ \\
\hline \multirow{2}{*}{ \%BW Knee Extension (Nm) } & $60^{\circ} \cdot \mathrm{s}^{-1}$ & $277.9 \pm 34.2$ & $275.0 \pm 33.6$ \\
\hline & $240^{\circ} \cdot \mathrm{s}^{-1}$ & $108.8 \pm 8.7$ & $122.0 \pm 21.8$ \\
\hline \multirow{2}{*}{ \%BW Knee Flexion (Nm) } & $60^{\circ} \cdot \mathrm{s}^{-1}$ & $211.1 \pm 31.8$ & $227.2 \pm 38.6$ \\
\hline & $240^{\circ} \cdot \mathrm{s}^{-1}$ & $133.7 \pm 22.6$ & $157.0 \pm 31.4$ \\
\hline \multirow{2}{*}{ Flexion/Extension (H/Q) ratio } & $60^{\circ} \cdot \mathrm{s}^{-1}$ & $76.2 \pm 8.6$ & $83.1 \pm 13.7$ \\
\hline & $240^{\circ} \cdot \mathrm{s}^{-1}$ & $84.8 \pm 12.0$ & $95.9 \pm 13.3$ \\
\hline
\end{tabular}
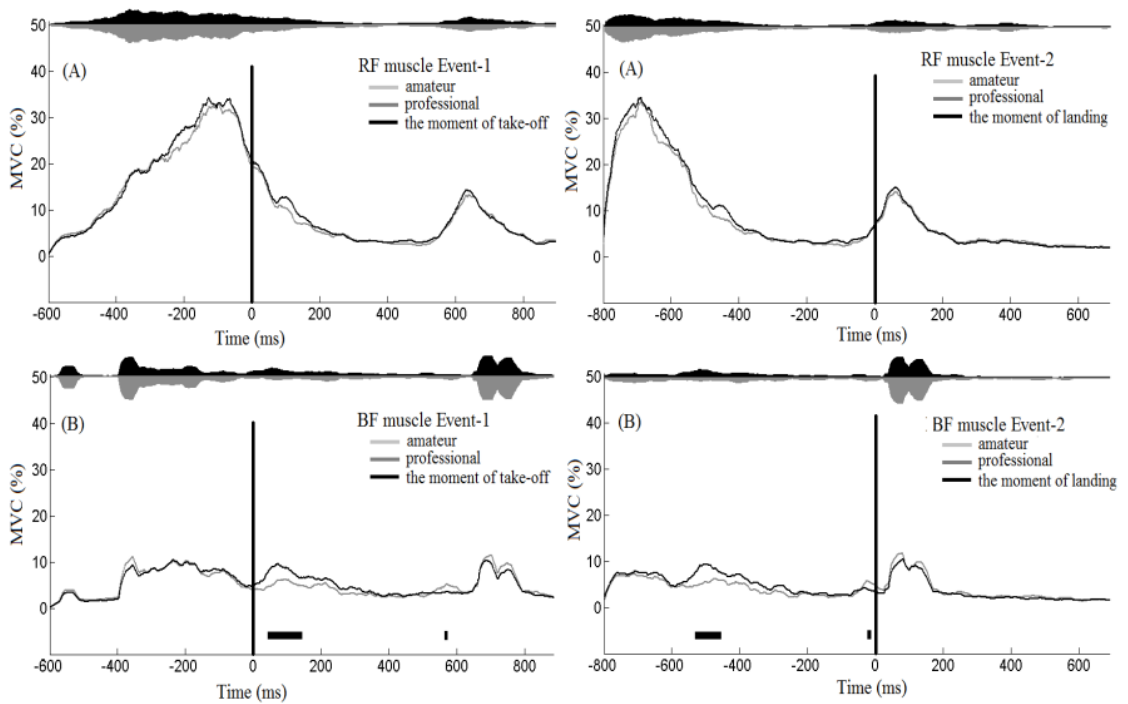

Figure 1. Muscular activation of RF and BF in professional and amateur soccer players during countermovement jump. 
The peak muscular activations for VM $(45 \%$ MVIC), VL (30\% MVIC), RF (\%35 MVIC), GAS (\%35 MVIC) occurred during propulsion phase, while peak activations for BF occurred (15\% MVIC) during post landing phase. For RF there were no statistically significant differences $(p>0.05)$ between groups in the way of event 1 and 2 (Figure 1a). The only BF muscle significant differences $(p<0.05)$ occurred in flight phase for event 1 (between 30$150 \mathrm{~ms}$ and $550-570 \mathrm{~ms})$ and event $2(-550$ and $-450 \mathrm{~ms}$ and -20 and $-10 \mathrm{~ms}$ ) and professionals showed higher activation levels than amateurs (Figure 1b).

Moreover, while significant differences $(p<0,05)$ occurred both for event 1 (between 100-120ms) and event 2 (between -470 and $-450 \mathrm{~ms}$ ) in $\mathrm{VL}$, the only significant differences occurred during flight time for $\mathrm{VM}$ in event 1 (between 100-120ms) with professionals showing higher activation than amateurs (Figure $2 \mathrm{a}$ and $2 \mathrm{~b}$ respectively). For GAS, significant differences $(p<0,05)$ occurred during the propulsion (between -300 and $-50 \mathrm{~ms}$ in the side of event 1) and flight phase (between 170-360ms for the side of event $1 ;-420$ and $-200 \mathrm{~ms}$ in the side of event 2) with professionals showing higher activation levels than amateurs (Figure 3).

\section{DISCUSSION}

In line with our hypothesis, this study points out important findings between the professional and amateur soccer players, which are in the same age group and have similar training experience. (i) CMJ height and power are higher in professionals than amateurs (ii) The main findings indicate that muscular activation strategies to explosive movement such as CMJ differ between professional and amateur soccer players (iii) The strength of the knee flexor differs between groups, with professional players having stronger hamstrings than amateurs, especially for movements at higher angular velocities (iv) Isokinetic strength was related to absolute and relative concentric extensor strength, but the H/Q strength ratio did not vary between groups.
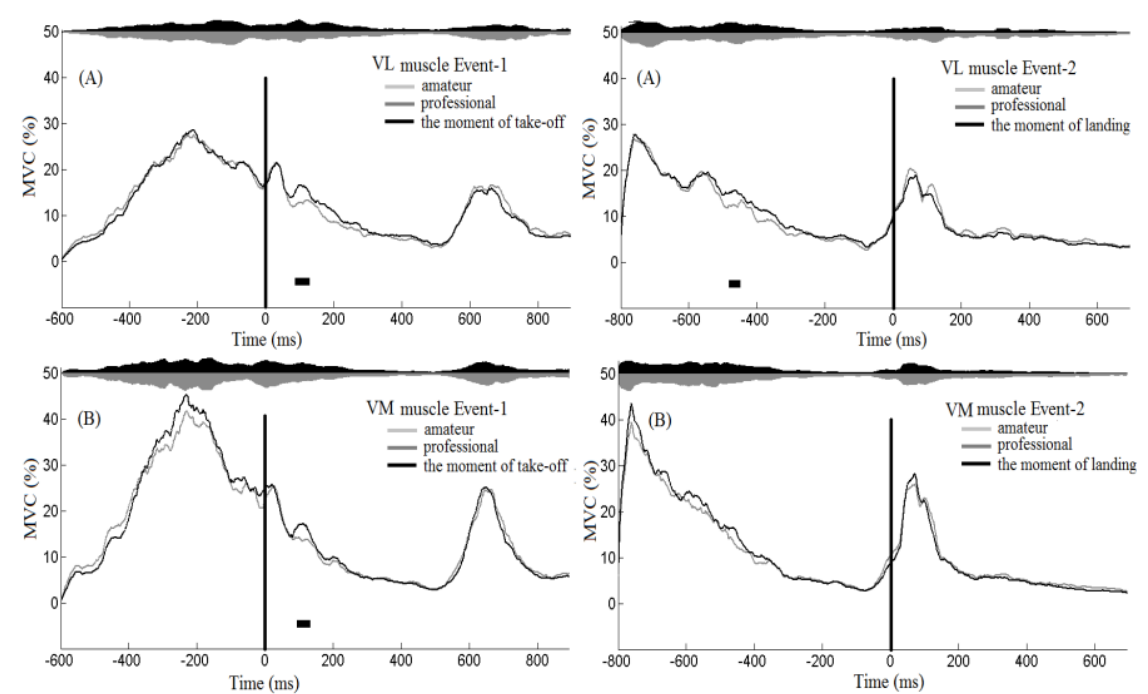

Figure 2. Muscular activation of VL and VM in professional and amateur soccer players during countermovement jump.
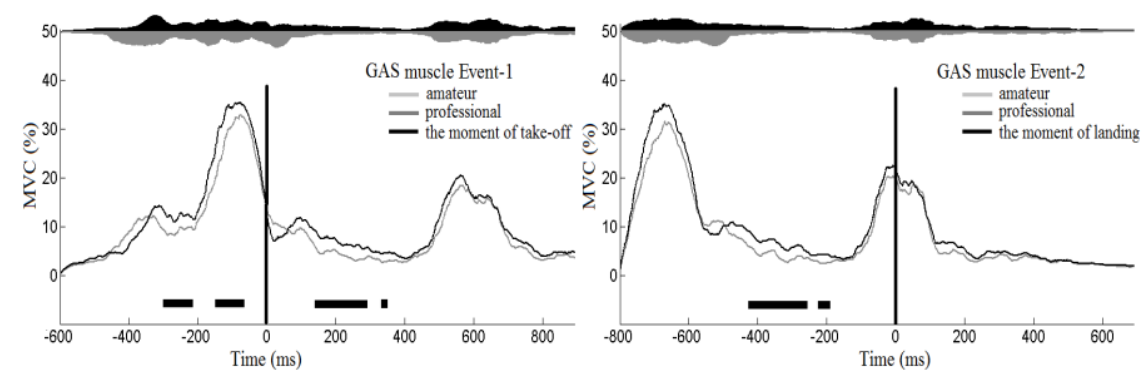

Figure 3. Muscular activation of GAS in professional and amateur soccer players during countermovement jump. 
Numerous studies have measured countermovement jump height as indicator of muscle power of the lower limbs in soccer players. The jump heights obtained in the present study were similar (9) or lower (30) than previous literature on professional soccer players.

To the authors' knowledge, there is no study regarding the EMG activity differences between amateur and professional soccer players during countermovement jump with time domain analyses, while limited studies have been conducted to analyze lower body muscle activation differences during vertical jump in different populations $(12,15$, 23 , 28).Previous studies have focused on joint kinetics to examine the mechanical strategy of vertical jumping, however the results are conflicting. Hubley and Wells (15) analyzed both CMJ and SJ without arm swing and found the relative joint contribution to the total work done on the center of mass (COM). Their results revealed that the greatest contributor to the total work done was the knee $(49 \%)$, followed by the hip (28\%) and ankle $(23 \%)$. However, Fukashiro and Komi (12) performed a similar study within one person and found the contribution of the lower leg as the hip (51\%) followed by the knee $(33 \%)$ and the ankle $(16 \%)$. Vanezis and Lees (28) aimed to quantify certain kinematic and kinetic variables for good and poor performers of vertical jump. The authors found that good jumpers exhibited significantly greater ankle work than poor jumpers, but no significant differences were found at the hip or knee.

Jakobsen et al., (17) analysed CMJ performance of untrained males after 12 weeks of progressive heavy-resistance strength training. They reported that $\mathrm{CMJ}$ performed faster in the take-off phase and muscle power production is increased and caused explosive-type SSC muscle performance. In addition, they underline the importance of planter flexor muscle contribution on force and power pruduction in the late take-off phase of CMJ. It is stated that planter flexor EMG activation increases in the final plantar flexor phase.

As a result of these conflicting findings it is certain that jumping performance is primarily related to lower leg power generation. However, the amount of power that each muscle contributes to a maximal jump is dependent on the jump condition (20), the subject's experience, and skill level (28).

Another study reported EMG data related to jump performance in futsal athletes. Differences between best and worst squat jump performance in futsal players (23). Four muscles were observed, as with the present study (RF, BF, VM and GAS), and it was concluded that $400 \mathrm{~ms}$ before the take-off phase there was no statistically significant differences amongst muscles in different jumps. Furthermore, Pereira et al. (23) exhibited negative effect of earlier activation of the BF muscle in vertical jumps and they stated that this is reduced moment of force at the knee and the hip without efficient transfer of force between them. Oliver et al. (21) investigated acute effects of completing soccer-specific exercise on SSC jump performance, and changes in muscle activity and ground reaction force data in three different jump performances. Only the two muscles (VL and $\mathrm{BF}$ ) were common with the present study and the others were tibialis anterior and soleus. They stated that EMG activity change according to jump type that drop jump showed a significant reduction $(\mathrm{P}<0.05)$, countermovement jump reduction approached significance $(P>0.065)$ and the squat jump changes were non-significant $(P>0.16)$ in the case of EMG activity following the soccerspecific intermittent exercise test (21).

A general interpretation of the muscle activity over the time window used in the current study reflects the propulsion push-off, flight and post landing phases whose general timings were established from the TTL signal of our switch mat. According to the results, even though the time and amplitude values demonstrate similar characteristic in both amateur and professional soccer players, the results revealed significant differences $(p<0.05)$ between professional and amateur soccer players' muscular activation strategies during propulsion push-off and flight phase of CMJ. There appears to be three main parts of the action where professionals demonstrate superior kick performance. The first is before jump movement at the start of the propulsion phase push-off. Here activation of GAS occurred earlier in amateurs, which shows the longest push-off time from about $300 \mathrm{~ms}$ before take-off, there were significant differences $(p<0.05)$ with little peak in GAS muscle and professionals demonstrated higher activation than amateurs. Activation in VL and VM peaked in the middle of propulsion phase while activity of RF and GAS reached peak just before take-off, where concentric activation phase (upward COM movement). However, in the BF muscle there was little activity at that time. Baratta et al., (3) reported that quadriceps muscle activity was greater than hamstring muscle activity during functional movement like in the current study because co- 
activation of the lower extremity muscles were assumed to improve the stability of the knee joint (24). Furthermore, the most important findings of the current study GAS activation differences $(p<0.05)$ between professional and amateur soccer in push off phase. GAS muscle is a biarticular muscle that is passing the knee and the ankle joints and acts as a knee flexor and ankle extensor. In jumping, the activation of the biarticular GAS muscle prior to the end of the push-off enables the transportation of the power generated by the knee extensors from the knee to the ankle joint. As a result, mechanical energy is transferred from the proximal joints to the distal joints (2). Taken together these data suggest that the professionals had a more effective action going into the CMJ. Secondly, once the athletes reached the takeoff phase, there was a marked reduction in all muscle activity and significant differences $(p<0.05)$ occurred between groups in $B F$ (between 30-150ms in event 1), VL and VM (between 100-120ms in event 1) in flight phase. However, significant differences $(\mathrm{p}<0.05)$ in GAS muscle occurred late in the flight phase (between 420 and $-200 \mathrm{~ms}$ in event 2) with higher activity in professional soccer players. The activation of the GAS muscle before ground contact is thought to stiffen the ankle joint in preparation for touch down, while performing knee flexion (16). Activity in all muscles over this period was present, but was low until the landing moment. Pre-activity in GAS started just before landing.

Thirdly, just after ground contact, RF, VM, VL and BF muscle activation occurred. This allows for the body to decelerate slowly as the feet touch the ground. These results were gathered from two different soccer levels (amateur and professional), which are same age group and training experience, but differ in jump power and hamstring strength.

These general interpretations allow comments to be made on some issues related investigating mechanisms underpinning CMJ performance. There is the issue of the "Stretch Shortening Cycle (SSC)" which the muscle action enhances the performance as compared to the pure concentric actions of the isolated muscle by a fast downward and upward acceleration of the center of mass (COM). Therefore, the short lasting phase of propulsive concentric muscle contractions is of essential importance for CMJ (4). During SSC, the importance of monoarticular muscles (VL and VM) and the bi-articular muscle (BF, RF, GAS) activation can be dependent on the phase of jump and the condition of the jump (arms free or not, knee and hip dominant, squat and countermovement jump). Jacobs et al., (19) proposed the importance of bi-articular muscles that they identified $\mathrm{RF}$ is responsible for the power transfer from the hip to the knees, while in contrast the kinematic analysis during jumps showed that hamstrings were involved in the power transfer from the knees to the hip. The result of the simultaneous contraction of these antagonist muscles is the net transfer of force from the hip to the knees, which is the role of SSC. This means that quicker energy transfer from proximal to distal body segments causes higher takeoff velocities. In the current study, the SSC during push-off time was almost the same between professional and amateurs according to the BF, RF VL and VM muscles activity. However, the GAS, the most determinant biarticular muscle is activated higher in professionals than that of amateurs just before take-off during push-off phase. This findings support the idea, which was developed by Vanezis and Lees (28) that the ankle power is important to determine high performance during CMJ and Jakobsen et al., (17) that the plantar flexor muscles are important contributors to force and power production in the late take-off (plantar flexor) phase of maximal vertical CMJ.

The total and average power was significantly higher for professionals in the current study. The main limitation of the present study was that power was estimated using an equation that predicts power output from jump height and the subject's body mass instead of individual joint (knee, hip, and ankle) kinetic analyses. The lack of significant differences between professionals and amateurs may be due to athletes being the same age, soccer experience, and playing position. In addition, lack of significant differences between knee flexor and extensor muscles may have been due to the testing protocol, where the knee angle was between $80-90^{\circ}$ and arms not free. This may have resulted in the present research finding significant differences regarding GAS muscle during late push-off. This demonstrates the importance of biarticular muscle actions at latest stage of proximal to distal segment energy transfer in CMJ. According to our estimations of jump power using the prediction equations and measurements of EMG activity, we can conclude that the professionals generate more power than the amateurs with the high activation of GAS muscle as well as RF, VL and VM muscles.

In conclusion, the results of the current study revealed that the both professionals and amateurs performed the CMJ from proximal to distal 
segments. The pre-activation and post landing phase are important for both groups; however; the high activation of GAS muscle could be one of the important determinants for superior vertical jump performance especially if the age, training experience, and strength parameters are almost similar. According to our findings and the literature, SSC training regarding hip, knee, and ankle should be performed to improve CMJ. Squat jumps or olympic weightlifting movements like the power clean and snatch help develop quadriceps and hamstring and also calf strength and coordination (26). Therefore, coaches and players should perform SSC strength training rather than isolated concentric or eccentric strength training.

\section{REFERENCES}

1. Aagaard P, Simonsen EB, Andersen JL, Magnusson P, DyhrePoulsen P. Increased rate of force development and neural drive of human skeletal muscle following resistance training. Journal of Applied Phycology, 2002; 93:1318-1326.

2. Babic J, Lenaric J. Vertical Jump: Biomechanical Analysis and Simulation Study Humanoid Robots. Slovenia: Publisher ITech Education and Publishing, 2007; 552-565.

3. Baratta R, Solomonow M, Zhou BH, Letson D, Chuinard R, D'Am- brosia R. Muscular coactivation: the role of the antagonist muscula- ture in maintaining knee stability. The American Journal of Sports Medicine, 1988; 16: 113-22.

4. Bobbert MF, Gerritsen KG, Litjens MC, Van Soest AJ. Why is countermovement jump height greater than squat jump height? Medicine \& Science in Sports \& Exercise, 1996; 28(11): 1402-1412.

5. Bosco C, Viitasalo JT. Potentiation of myoelectrical activity of human muscles in vertical jumps. Electromyography and Clinical Neurophysiology, 1982; 22: 549-562.

6. Canavan PK, Vescovi JD. Evaluation of power prediction equations: peak vertical jumping power in women. Medicine \& Science in Sports \& Exercise, 2004; 36(9): 1589-1593.

7. Carlock JM, Smith SL, Hartman MJ, Morris RT, Ciroslan DA, Pierce KC, Newton RU, Harman EA, Sands WA, Stone MH. The relationship between vertical jump power estimates and weightlifting ability: a field-test approach. The Journal of Strength \& Conditioning Research, 2004; 18(3): 534-539.

8. Cerrah AO, Onarici Gungor E, Soylu AR, Ertan H, Lees A, Bayrak C. Muscular Activation patterns during the Soccer InStep Kick. Isokinetics and Exercise Science, 2011; 19: 181-190.

9. Cometti G, Maffiuletti NA, Pousson M, Chatard JC, Maffulli $\mathrm{N}$. Isokinetic strength and anaerobic power of elite, subelite and amateur French soccer players. International Journal of Sports Medicine, 2001; 22(1): 45-51.

10. Cormie P, McGuigan MR, Newton RU. Adaptations in athletic performance after ballistic power versus strength training. Medicine \& Science in Sports \& Exercise, 2010; 42: $1582-1598$

11. Edwards S, Steele JR, Cook JL, Purdam CR, McGhee DE. Lower limb movement symmetry cannot be assumed when investigating the stop-jump landing. Medicine \& Science in Sports \& Exercise, 2012; 44(6): 1123-1130.

12. Fukashiro S, Komi PV. Joint moment and mechanical flow of the lower limb during vertical jump. International Journal of Sports Medicine, 1987; 8: 15-21.

13. Gerodimos V, Zafeiridis A, Perkos S, Dipla K, Manou V, Kellis S. The contribution of stretch-shortening cycle and armswing to vertical jumping performance in children, adolescents, and adult basketball players. Pediatric Exercise Science, 2008; 20(4): 379 - 89.

14. Hertogh C, Hue O. Jump evaluation of elite volleyball players using two methods: jump power equations and force platform. The Journal of Sports Medicine and Physical Fitness, 2002; 42: 300-303.

15. Hubley CL, Wells RP. A Work-Energy Approach to Determine Individual Joint Contributions to Vertical Jump Performance. European Journal of Applied Physiology and Occupational Physiology, 1983; 50: 247-254.

16. Horita T, Komi PV, Nicol C, Kyröläinen $H$. Interaction between pre-landing activities and stiffness regulation of the knee joint musculoskeletal system in the drop jump: implications to performance. European Journal of Applied Physiology, 2002; 88(1-2): 76-84.

17. Jakobsen MD, Sundstrup E, Randers MB, Kjær M, Andersen LL, Krustrup P, Aagaard P. The effect of strength training, recreational soccer and running exercise on stretch shortening cycle muscle performance during countermovement jumping. Human Movement Science, 2012; 31(4): 970-986.

18. Johnson DL, Bahamonde R. Power output estimate in university athletes. The Journal of Strength \& Conditioning Research, 1996; 10(3): 161-166.

19. Jacobs R, Bobbert MF, Ingen-Schenau GJV. Mechanical output from individual muscle during explosive leg extensions: the role of biarticular muscles. Journal of Biomechanics, 1996; 29(4): 513-523.

20. Kakihana W, Suzuki S. The EMG activity and mechanics of the running jump as a function of takeoff angle. Journal of Electromyography \& Kinesiology, 2001; 11(5): 365-372.

21. Oliver J, Armstrong N, Williams C. Changes in jump performance and muscle activity following soccer-specific exercise. Journal of Sports Science, 2008; 26(2): 141-148.

22. Onarıcı Güngör E., Cerrah A.O., Soylu A.R., Ertan H., Sevil G., Muscular Activation Strategies during Countermovement Jump in Female Volleyball, International Association of Computer Science in Sport, Proceedings of the Seventh International Symposium, 2009, 136-146.

23. Pereira R, Machado M, Miragaya dos Santos M, Pereira LN, Sampaio-Jorge F. Muscle activation sequence compromises vertical jump performance. Serbian Journal of Sports Sciences, 2008; 2(14): 85-90.

24. Perotto AO. Anatomical guide for the electromyography: the limbs and the trunk. Springfield, IL: Charles C. Thomas, 1994.

25. Stolen T, Chamari K, Castagna C, Wisløff U. Review article: physiology of soccer. Sports Medicine, 2005; 35 (6): 501-536.

26. Stone MH, Stone ME, Sands WA. Principles and Practice of Resistance Training. Champaign, IL: Human Kinetics, 2007.

27. Urabe Y, Kobayashi R, Sumida S, Tanaka K, Yoshida N, Nishiwaki GA, Tsutsumi E, Ochi M., Electromyographic 
analysis of the knee during jump landing in male and female athletes. Knee, 2005; 12(2): 129-134.

28. Vanezis A, Lees. A, Biomechanical analysis of good and poor performers of the vertical jump. Ergonomics, 2005; 11: 15941603.

29. Vescovi JD, Brown TD, Murray TM. Descriptive characteristics of NCAA Division I women lacrosse players. Journal of Sport Science and Medicine in Sport, 2007; 10(5), 334-340.
30. Wisløff U, Castagna C, Helgerud J, Jones R, Hoff J. Strong correlation of maximal squat strength with sprint performance and vertical jump height in elite soccer players. British Journal of Sports Medicine, 2004; 38: 285-288. 